\title{
PHENOLOGICAL PLASTICITY IN BERBERIS LYCIUM ROYLE ALONG TEMPORAL AND ALTITUDINAL GRADIENTS
}

\author{
RAHMAN, I. U. ${ }^{1,2 \S}-$ HART, R. ${ }^{2}-$ AfZAL, A. ${ }^{*}$ - IQBAL, Z. ${ }^{1}-$ ABD_ALlAH, E. F. ${ }^{3 \dagger}-$ \\ Alqarawi, A. A. ${ }^{3}-$ IJAZ, F. $^{1}-$ Ali, N. ${ }^{1}-$ KAUSAR, R. ${ }^{4}-$ MuZAMmiL, S. ${ }^{5}-$ AlZAin, M. N. \\ O. ${ }^{6}-$ MAJID, A. ${ }^{1}-$ CALIXTO, E. S. ${ }^{7}$ \\ ${ }^{1}$ Department of Botany, Hazara University, Mansehra-21300, KP, Pakistan \\ ${ }^{2}$ William L. Brown Center, Missouri Botanical Garden, P.O. Box 299, St. Louis, MO 63166- \\ 0299, USA \\ ${ }^{3}$ Department of Plant Production, College of Food \& Agricultural Sciences, King Saud \\ University, P.O. Box 2460, Riyadh 11451, Saudi Arabia \\ ${ }^{4}$ Department of Environmental Sciences, International Islamic University, Islamabad, Pakistan \\ ${ }^{5}$ Department of Biological Sciences, Faculty of Science, King Abdulaziz University, Jeddah \\ 21589, Saudi Arabia \\ ${ }^{6}$ Princess Nourah bint Abdulrahman University, College of Science, Biology Department, \\ Riyadh 11451, Saudi Arabia \\ ${ }^{7}$ Department of Biology, University of Sao Paolo, SP, Brazil \\ *Corresponding author \\ e-mail:aftabafzalkiani@yahoo.com
}

${ }^{\S}$ ORCID ID: 0000-0003-3312-7975; ‘0000-0002-8509-8953

(Received 24 $4^{\text {th }}$ Jul 2018; accepted $16^{\text {th }}$ Oct 2018)

\begin{abstract}
Human influence on the climate change is evident, and the current rate of anthropogenic emissions of greenhouse gases will have widespread impacts on natural ecosystems. Moreover, as global mean temperatures continue to rise; it is pivotal to develop strategies to conserve species and habitats that are vulnerable to climate change. Therefore, the current study assessed the effect of changing climate on fruiting time and phenological plasticity in Berberis lycium Royle at Manoor Valley of Northern Pakistan. Further, these changes in fruiting behavior were correlated with temperature changes over the years. Five varying altitudinal sites of Manoor Valley were selected viz. Kot, Baila Manoor, Banrhi, Siri and Shamal Pata which range between 1807-2390 m.a.s.l. Observational data on phenological stage of B. lycium were recorded in May-October of 2015-17. Ten individuals plant were randomly selected at each altitudinal site and the data recorded. Notable traits were; cover, number of mature fruits and number of immature fruits. GPS was used to record elevation, aspect and position of the plant species and other environmental gradients were measured with the help of weather station. The results were validated using the ordination pattern. Significant changes were observed in all parameters of the species. The results indicated highest gain for bioclimatic variable (bio-9, mean temperature of the driest quarter). The data also indicates that B. lycium is highly sensitive to changes in altitude and temperature; it may be adapting to the gradual temperature change over long periods of time by altering the fruiting time or by adjusting to new altitudinal ranges. Furthermore, new phenology patterns and variations of fruiting period in B. lycium might be the indication of the raise in global temperature.
\end{abstract}

Keywords: ecophysiology, climate change, global warming, phenological patterns, Lesser Himalayas 


\section{Introduction}

The world temperature is rising, and thus warming of the climate is unequivocal. Since 1950s, many of the observed changes are unprecedented over decades to millennia and the earth's temperature has risen up to $0.74^{\circ} \mathrm{C}$ and is likely to increase from $1.8^{\circ} \mathrm{C}$ to $4^{\circ} \mathrm{C}$ by 2100 (IPCC, 2007). In recent years, global climate change has threatened environments with increasing global temperatures (IPCC, 2013). This change in climate is occurring due to increased urbanization, and rising concentrations of carbon dioxide stemming from the anthropogenic burning of fossil fuels, which gets trapped into the atmosphere and cause global warming (Bashir and Ahmad, 2017). These changes have the potential to affect species interactions (Walther, 2010). During the postglacial period, species and populations responded to global warming by migrating toward higher latitudes or altitudes, resulting in local extinctions and modifications in species distributions (Petit et al., 2003). However, populations could persist in their current location and withstand environmental stresses if they evolve new adaptive capacities (Lindner et al., 2009). Genetic diversity and phenotypic plasticity are the two key processes that allow plants survival and development under varied environmental regimes (Pigliucci et al., 2006). First, high genetic diversity among and within populations would improve opportunities for rapid adaptation to new environmental stimuli (Hamrick, 2004). Secondly, short-term phenotypic plasticity is a significant means whereby, plants can react and cope with rapid environmental change (Ghalambor et al., 2007). Genetic variability and evolution among organisms at the DNA level is a much-needed resource but takes millions of years. Therefore, under rapid climate change, phenotypic plasticity rather than genetic diversity will likely play a crucial role in allowing plants to persist in their environments (Rehfeldt et al., 2001).

Phenology — the timing of life history stage including the flowering, fruiting, and leaf production of plants - is sensitive to abiotic cues such as day length, temperature and precipitation (Gilman et al., 2010, Cleland et al., 2007). At the same time, biotic factors also influence phenology; plants that are able to respond to seasonal variability are better adopting to maximize the success of their offspring (Hamann, 2004).

It is known that altitude represents a complex gradient along which many environmental variables change concomitantly (Givnish, 1999). Altitudinal gradients are particularly relevant in order to study plant phenological responses to temperature because they provide a wide temperature range over a very short distance. Phenological plasticity is of special importance for species located in mountain habitats since it is much more likely that their offspring will experience a different climate than their parents, if seed dispersal occurs at a relatively short distances up or down the mountain. This change has been widely documented in many studies as evidence of the impact of global climate change on ecosystems, and a considerable amount of studies have focused on temperate as opposed to environments (Sherry et al., 2007). Monitoring changes in the phenology of plants can provide insights as to which plant species are responding to altered climate patterns and is an important indicator as to whether an ecosystem is experiencing a shift. As plant species shift upward in altitude, populations decrease and elevation ranges tend to be smaller than those for temperate species (Colwell et al., 2008).

Flowering and leaf-out phenologies and their responses to climate change have historically been well-studied. In contrast, fruiting phenology responses to climate change have received somewhat less attention, despite the fact that they are critical to reproduction and therefore the persistence and adaptation of populations (Bolmgren and 
Lonnberg, 2005). Further, the phenologies of many economically and ethnobotanically important fruits are likely to change with climate change, lending a human dimension to the urgency of studying this life-history stage (Chuine et al. 2004).

Berberis lycium Royle (family: Berberidaceae) is a lesser-known plant, named in English as barberry (Anwar et al., 1979), whereas its fruit is called as "Kashmal" (Usmanghani et al., 1997) and its roots are known as "Darhald" (Nadkarni, 1980). It is native to the Himalayan region of the world and is widely distributed in temperate and semi-temperate areas of Pakistan, India, Afghanistan, Nepal and Bangladesh. In Pakistan, it has historically been recorded as growing in Baluchistan, Khyber Pakhtunkhwa, Punjab and Azad Kashmir at an elevation of 900 to $2900 \mathrm{~m}$ (Ali and Khan, 1978). According to the International Union for Conservation of Nature (IUCN), B. lycium lies in the vulnerable category (Hamayun et al, 2006).B. lycium was reported curing leprosy in Unani system of healthcare. In traditional practices, it is extensively used as medication for several human diseases i.e. broken bones, jaundice, menorrhagia and wounds healing (Singh and Rawat, 2000), acute conjunctivitis, aperient, carminative, colic, ophthalmic inflammation, diarrhea, diuretic, dysentery, expectorant, febrifuge, stomachic and throat infection (Gupta et al., 2015).

The current study was planned to assess phenological plasticity in this important medicinal shrubby plant species along temporal and elevational gradients. In particular we compared contemporary fruiting phenologies to historical norms to elucidate changes over time, and examined environmental conditions along an elevational gradient to link these changes to climate. .

\section{Materials and Methods}

Research was undertaken in Manoor Valley, Mansehra, Pakistan (Fig. 1). The study area ranges from high subtropical to alpine scrub forest and cold deserts and experiences cloud cover during most of the year. Five varying altitudinal sites were selected for this study on the basis of the species abundance and dominance. These were Kot (1807 m), Baila Manoor (1895 m), Banrhi (2019 m), Siri (2155 m) and Shamal Pata (2390 m).

At each site, elevation was recorded with GPS and aspect with clinometer. During monthly visits throughout the growing season (April-September) 2015-2017, environmental factors (wind speed, temperature, humidity, heat index, dew point, wet bulb and barometric pressure) were measured by handheld weather station (Kestrel weather tracker 4000). For 10 Berberis lycium individuals selected randomly during each visit, the cover, the number of immature fruits, and the number of mature fruits were measured.

These data were then compared to phenological patterns of B. lycium as characterized in the Flora of Pakistan - a range based on historical specimens collected mostly between 1939 and 1975 - to determine the long-term seasonal change in fruiting behavior.

To characterize the similarity among sites in cover and summer-fruiting phenology we conducted two-way cluster analysis (Bano et al., 2018) based on presence/absence scores in PCORD 5, and a ternary plot (Hammer et al., 2001) based on quantitative values in PAST 3.12. To associate environmental conditions with differences in these response variables among sites, we used Canonical Correspondence Analysis (CCA), based on Bray-Curtis distance measures using CANOCO 5 (Lepš and Šmilauer, 2003). 


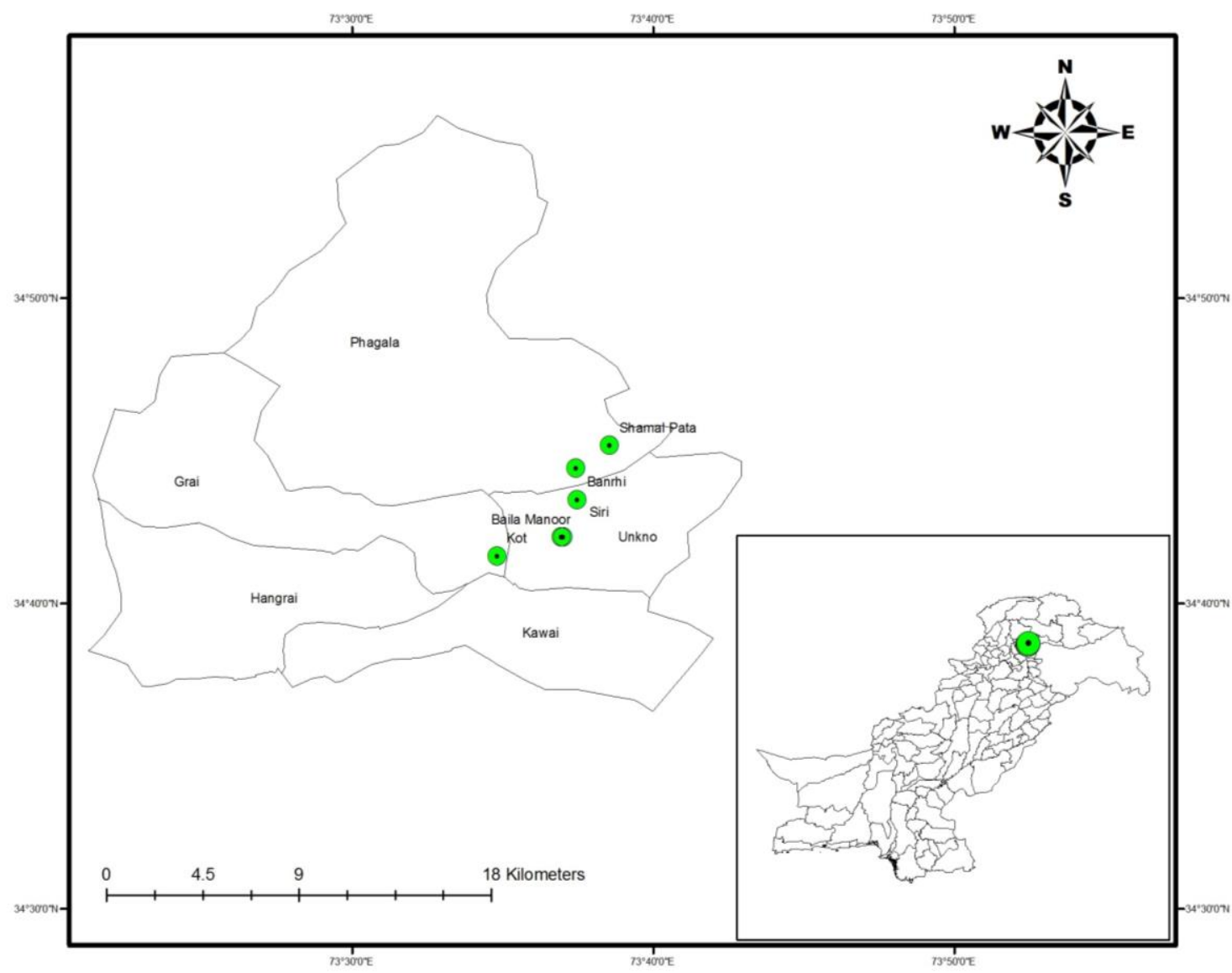

Figure 1. Map of the study area: Berberis lycium was studied at five locations (green dots) in Mansehra. The position of Mansehra is given in the inset map at bottom right

Table 1. Means across the growing season of environmental variables measured at different the six localities where Berberis lycium was recorded (wind speed averages are given as integers)

\begin{tabular}{|c|c|c|c|c|c|}
\hline \multirow{2}{*}{ Gradients } & \multicolumn{5}{|c|}{ Localities } \\
\hline & Kot & Baila Manoor & Banrhi & Siri & Shamal Pata \\
\hline Altitude (m) & 1807 & 1895 & 2019 & 2155 & 2390 \\
\hline Latitude & N 3469'282 & N 3470’323 & N 3472’364 & N 3470’317 & 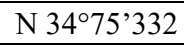 \\
\hline Longitude & 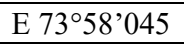 & E 7361’694 & $\mathrm{E}^{2} 3^{\circ} 62^{\prime} 488$ & E 7361'600 & E $73^{\circ} 64^{\prime} 278$ \\
\hline Slope angle & $45^{\circ}$ & $58^{\circ}$ & $65^{\circ}$ & $80^{\circ}$ & $30^{\circ}$ \\
\hline Temperature $\left({ }^{\circ} \mathrm{C}\right)$ & 31.3 & 29.2 & 25.6 & 23.7 & 21 \\
\hline Humidity & 47.5 & 60.3 & 50.8 & 68.9 & 71.9 \\
\hline Heat index & 32.5 & 30.4 & 24.4 & 24.4 & 20.5 \\
\hline $\begin{array}{c}\text { Wind speed } \\
(\mathrm{m} / \mathrm{sec})\end{array}$ & 1 & 0 & 1 & 0 & 1 \\
\hline Dew point & 18.9 & 20.3 & 15.1 & 17.6 & 15.7 \\
\hline Wet bulb & 22.3 & 22.2 & 18.5 & 19.4 & 17.3 \\
\hline $\begin{array}{c}\text { Barometric } \\
\text { pressure }\end{array}$ & 813.5 & 804.7 & 792.6 & 779.3 & 756.7 \\
\hline
\end{tabular}




\section{Results}

Berberis lycium was prominent at Kot, Baila Manoor, Banrhi, Siri and Shamal Pata areas of Manoor Valley, with varying fruiting phenology over geography and season (Fig. 2A-D). Cover of B. lycium was directly related to altitude, where higher vegetation cover at lower altitudes was observed ( 1800 m.a.s.l.).
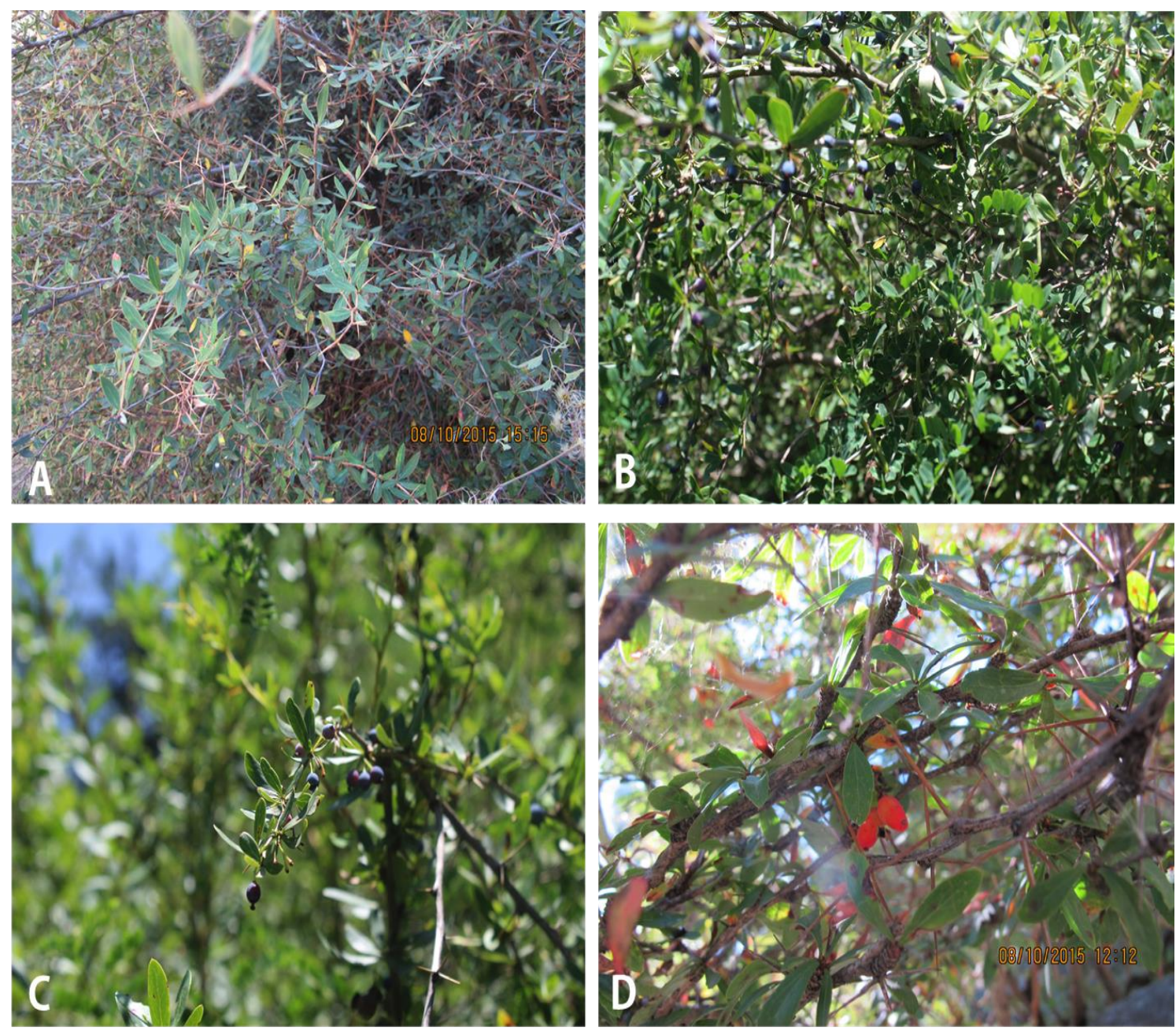

Figure 2. Phenological conditions of Berberis lycium captured at different stations. (A) No fruit at Baila Manoor, $(B)$ mature fruits at Banrhi, $(C)$ mature fruits at Siri, and (D) immature fruiting condition at Shamal Pata

Fruiting exhibited a similar pattern in each year, At the lowest elevation and relatively higher-temperature sites of Kot and Baila Manoor we observed a peak fruiting in spring, with roughly equal quantities of immature and mature spring fruits, while higher elevation sites had not yet begun to fruit in spring (Fig. 3). By summer, fruiting had completed at Kot, and progressively higher sites still retained greater quantities of mature fruits (Fig. 3). Only at the highest site, Shamal Pata, was fruiting still entering its peak in summer (Fig. 3). The ternary plot (Fig. 4) further supports the strong elevational gradient which differentiates sites on the basis of B. lycium cover and phenology. 


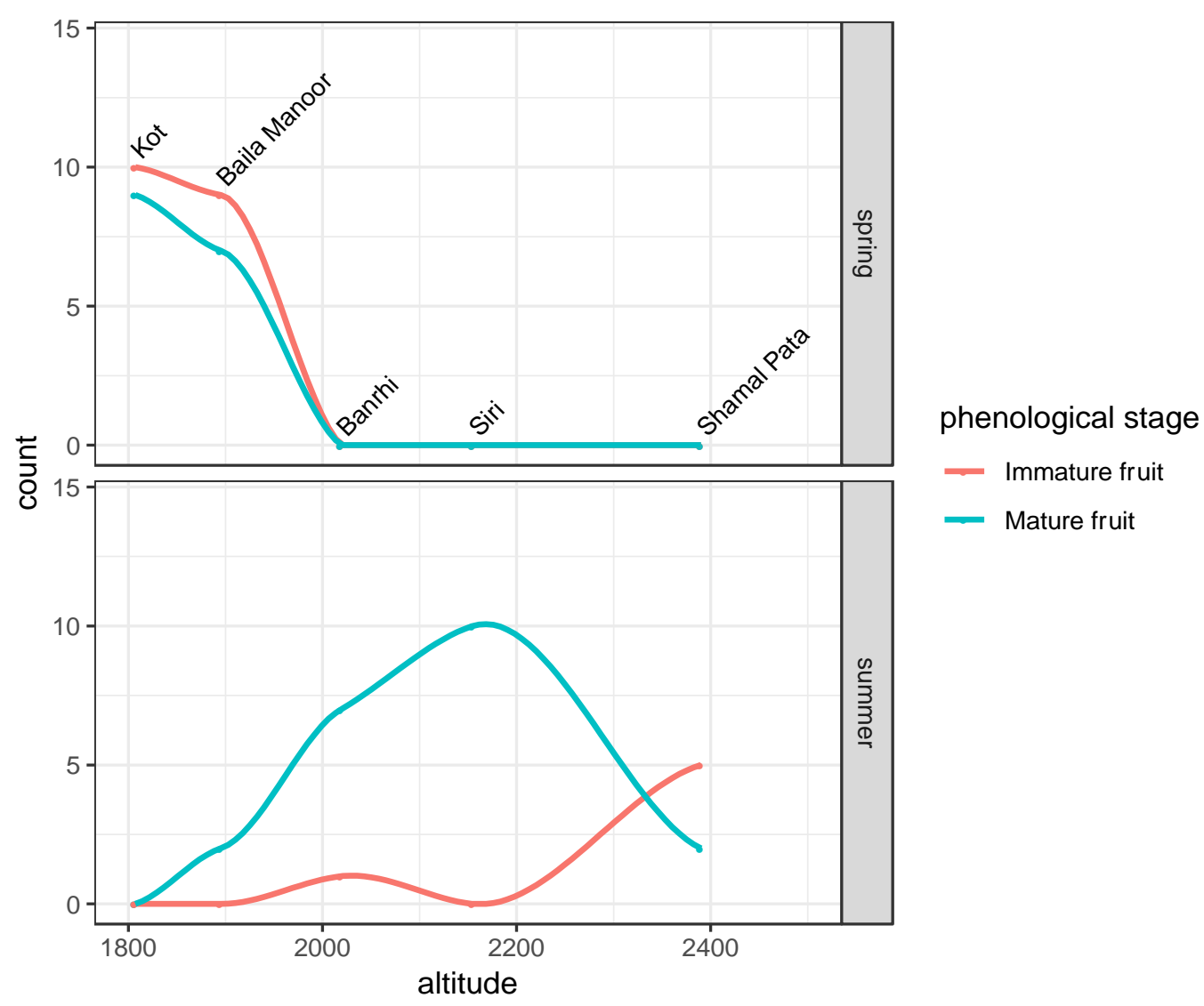

Figure 3. Elevational progression of fruiting phenology: lower elevation sites show peak fruiting in spring while higher sites have not yet begun to fruit; in summer, fruiting is finished at the lower elevation site, peaking at mid-elevations, and has yet to reach its peak at the highest elevation sites

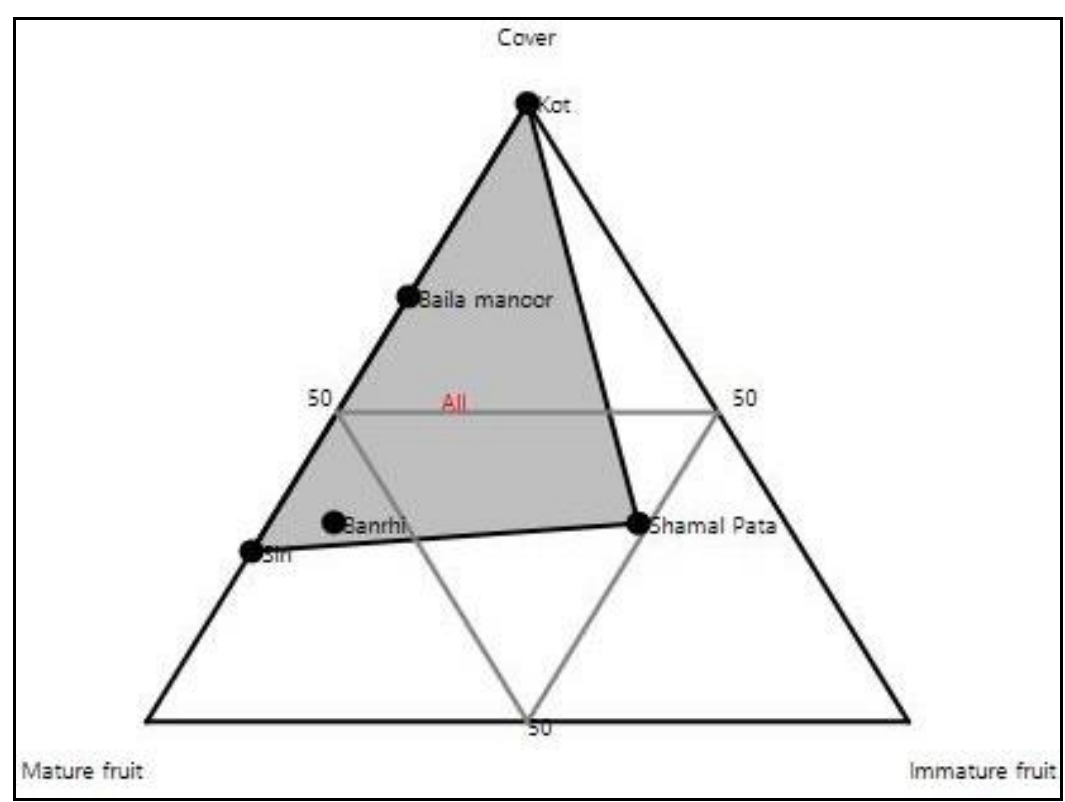

Figure 4. Ternary plot indicating the percentage of all the traits of Berberis lycium and its stations 
The CCA ordination (Fig. 5) of Berberis lycium attributes and environmental gradients showed that different attributes clustered along diverse environmental gradients, which may be summarized as representing the effects of elevation (altitude, temperature, heat index, barometric pressure) and of topography (wind speed, slope). The maximum Eigenvalue was recorded for axis $1(0.34)$ followed by axis $2(0.20)$. The percentage variance explained for axis 1 and 2 were $62.30 \%$ and $100 \%$ respectively. The total variation is 0.54 and the explanatory variables account for $100 \%$. The pseudocanonical correlation for axis 1 and 2 were 1.000 and 1.000. CCA ordination showed that higher values of temperature, barometric pressure, dew point, wet bulb, and heat index were parallel to lower humidity and elevation. Altitude showed negative and significant correlation with temperature, heat index and barometric pressure. Temperature showed positive and significant correlation with heat index and barometric pressure. The maximum strength of gradient was noticed for temperature, barometric pressure, wet bulb, heat index, altitude, density altitude, and slope angle. While minimum environmental gradient strength was observed for humidity, dew point and wind speed. Cover of Berberis lycium was significantly higher at the lower elevation sites (Kot and Baila Manoor at 1807-1895 m.a.s.1.). Among the higher sites, the steeper mid-elevation sites of Banrhi and Siri (2019-2155 m.a.s.l.) had the greatest counts of summer mature fruit, while summer immature fruit count was greatest at Shamal Pata (2390 m.a.s.l.), with a relatively shallow slope and high wind speeds (Fig. 5).

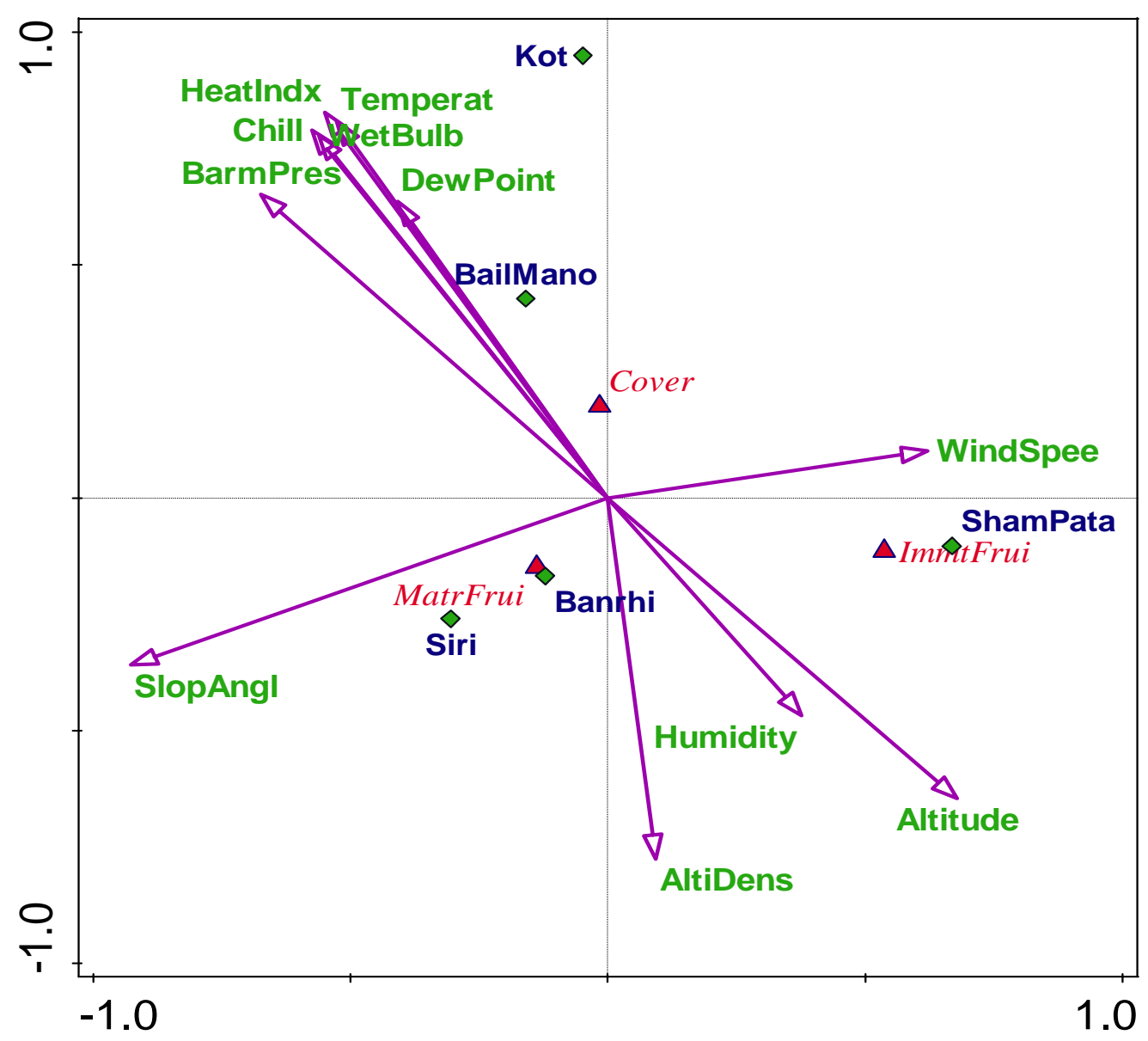

Figure 5. CCA ordination of Berberis lycium attributes and stations along different environmental variables 
In the Flora of Pakistan, the phenological period of Berberis lycium in the area mostly ends by July-August. However, we observe that this phenological period is now only evidenced at the highest altitudes (Shamal pata), while middle and lower elevation sites have completed their fruiting phenology much earlier (in spring, i.e. April-June) (Fig. 6). These higher sites are currently $5.5-10^{\circ}$ degrees cooler than the lower sites in average growing season temperature.

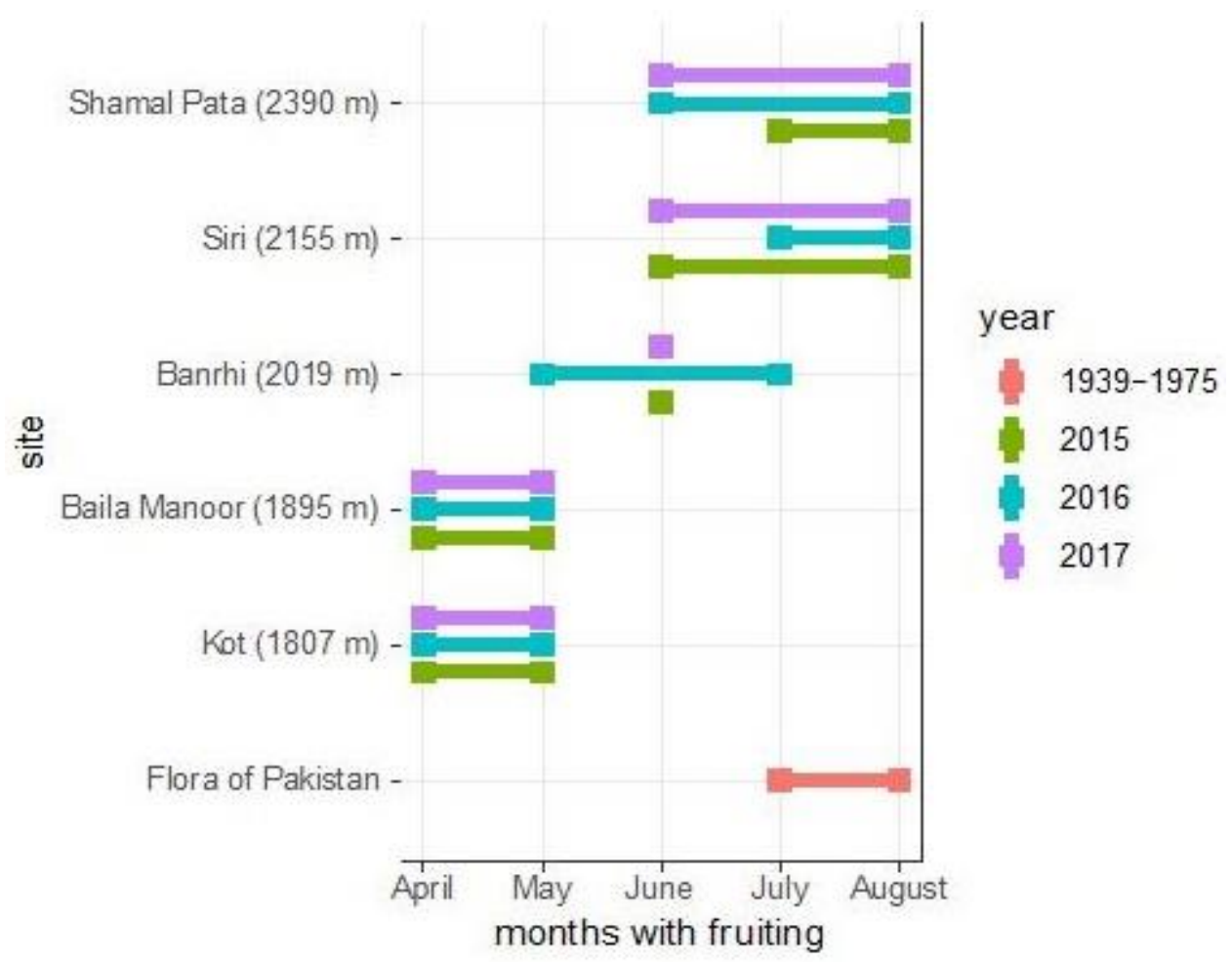

Figure 6. Phenological ranges in five sites monitored 2015-2017 are mostly earlier than phenological ranges recorded in the Flora of Pakistan (1939-1975), with only the highest elevation sites fruiting at comparable times

\section{Discussion}

Our results showed phenological variations along the altitudinal gradient, where climatic conditions, especially those related to changes in temperature, had determining roles. The disastrous synchronous effects of climate change and land-use change are evident in Pakistan due to the decline of forest cover (Siddiqui et al., 1999). The recent global data released by NASA and the National Oceanic and Atmospheric Administration (NOAA) suggested that the years this study was conducted (2015-2017) were the hottest recorded, equal or greater to $2^{\circ} \mathrm{C}$ compared to an 1881-1910 baseline (NASA and NOAA, 2015). Local trends within the far-western Himalaya are more uncertain (Tewari et al. 2017), but there is evidence for warming in the area (Bhutiyani et al., 2010). Some species are very prone to minute changes in the climate as Beigh et al. (2005) pointed out for Aconitum heterophyllum in the complex Himalayan region.

The current study predicts similar results as the species will be changing its current habitat and the population density might be significantly affected. Early fruiting behavior was noticed in Kot and Baila Manoor sites, it might be due to the relatively 
higher temperatures at these sites. At highest elevation range of this study, immature fruiting condition was on peak, this variability in fruiting phenological pattern might be due to temperature, an important environmental driver, which significantly affects the lifespan of each biotic component of the ecosystem. These results highlight that a particular environmental variable has a great effect on the distribution and dominance of Berberis lycium in Manoor Valley. In mountain ecosystems, decrease in population sizes and even extinctions of such species are possible due to the migration of species from their habitat towards higher elevations (Gilman et al., 2010).

Parallel to phenological changes, one of the general trends of species in the HinduKush-Himalayan region, as elsewhere is a change in altitudinal ranges (Song et al., 2004), often in complex response to multiple environmental cues (Tewari et al., 2017). These changes of plant spatial and temporal ranges can result in reorganization of species, leading to the formation of novel communities. Individuals and species as a group deal differently with the variation in abiotic conditions, and thus the likelihood of novel communities' formation higher (Lurgi et al., 2012), with unpredictable consequences (Gilman et al., 2010), and the potential to affect ecosystem resilience (Walther et al., 2010).

In Berberis lycium, phenological variations were observed along elevational ranges, and between past and contemporary phenology. The importance of temperature in differentiation the phenology of populations along the elevational gradient suggests that this may also be a key factor in the changes seen over time, although precipitation, land use changes and sampling effort must also be considered (Daru et al 2018). In future work, long-term, cross-taxon monitoring at the level of individual plants could be joined to further research into the historical range and phenology of plant species to better understand how plant communities are responding to changing climatic conditions.

Author's Contributions. IUR conducted the fieldwork, collected data and plant species, FI helped in the herbarium work. AM identified the plants specimens and designed the map. IUR, RH drafted the manuscript and analyzed the data, NA helped in organizing the data. RH, AA and ZI supervised the work. RH, NA and EFA critically reviewed the manuscript. RH and IUR revised the manuscript, AAA, AMNO, ESC, RK and MS helped in revision. All the authors have read and approved the final manuscript.

Acknowledgements. First author would like to thank Higher Education Commission (HEC), Pakistan for granting scholarship under International Research Support Initiative Program (IRSIP) to conduct a research work at Missouri Botanical Garden, USA. The authors would like to extend their sincere appreciation to the Deanship of Scientific Research at King Saud University for its funding to the Research Group number (RG-1435-014).

\section{REFERENCES}

[1] Ali, M. N., Khan, A. A. (1978): Pharmacognostic studies of Berberis lycium Royle and its importance as a source of raw material for the manufacture of berberine in Pakistan. Pakistan Journal of Forestry: p26.

[2] Anwar, A. K., Ashfaq, M., Nasveen, M. A. (1979): Pharmacognostic Studies of Selected Indigenous Plants of Pakistan. - Pakistan Forest Institute, Peshawar, NWFP, Pakistan.

[3] Bano, S., Khan, S. M., Alam, J., Alqarawi, A. A., Abd_Allah, E. F., Ahmad, Z., Hashem, A. (2018): Eco-Floristic studies of native plants of the Beer Hills along the Indus River in the districts Haripur and Abbottabad, Pakistan. - Saudi Journal of Biological Sciences 25(4): 801-810. 
[4] Bashir, H., Ahmad, S. S. (2017): Delineation of Catastrophic Effects of Climate Modifications in Pakistan Using GIS and Remote Sensing. - Universal Journal of Engineering Science 5(1): 1-4.

[5] Beigh, S. Y., Nawchoo, I. A., Iqbal, M. (2005): Cultivation and conservation of Aconitum heterophyllum: A critically endangered medicinal herb of the Northwest Himalayas. Journal Herbs. Spices and Medicinal Plants 1: 47-56.

[6] Bhutiyani, M. R., Kale, V. S., Pawar, N. J. (2010): Climate change and the precipitation variations in the northwestern Himalaya: 1866-2006. - International Journal of Climatology: A Journal of the Royal Meteorological Society 30(4), 535-548.

[7] Bolmgren, K., Lonnberg, K. (2005): Herbarium data reveal an association between fleshy fruit type and earlier flowering time. - International Journal of Plant Sciences 166: 663670.

[8] Chuine, I., Beaubien, E. G. (2001): Phenology is a major determinant of tree species range. - Ecology Letters 4: 500-510.

[9] Cleland, E. E., Chuine, I., Menzel, A., Mooney, H. A., Schwartz, M. D. (2007): Shifting plant phenology in response to global change. - Trends in Ecology and Evolution 22(7): 357-365.

[10] Colwell, R. K., Brehm, G., Cardelús, C. L., Gilman, A. C., Longino, J. T. (2008): Global warming, elevational range shifts, and lowland biotic attrition in the wet tropics. Science 322: 258-261.

[11] Daru, B. H., Park, D. S., Primack, R. B., Willis, C. G., Barrington, D. S., Whitfeld, T. J. S., Seidler, T. G., Sweeney, P. W., Foster, D. R., Ellison, A. M. et al. (2018): Widespread sampling biases in herbaria revealed from large-scale digitization. - New Phytologist 217: 939-955.

[12] Ghalambor, C. K., McKay, J. K., Carroll, S. P., Reznick, D. N. (2007): Adaptive versus non-adaptive phenotypic plasticity and the potential for contemporary adaptation in new environments. - Functional Ecology 21: 394-407.

[13] Gilman, S. E., Urban, M. C., Tewksbury, J., Gilchrist, G. W., Holt, R. D. (2010): A framework for community interactions under climate change. - Trends in Ecology and Evolution 25: 325-331.

[14] Givnish, T. J. (1999): On the causes of gradients in tropical tree diversity. - Ecology 876: 193-210.

[15] Gupta, M., Singh, A., Joshi, H. C. (2015): Berberis lycium multipotential medicinal application: An overview. - International Journal of Chemical Studies 3(4): 10-13.

[16] Hamann, A. (2004): Flowering and fruiting phenology of a Philippine submontane rain forest: climatic factors as proximate and ultimate causes. - Journal of Ecology 92(1): 2431.

[17] Hamayun, M., Khan, S. A., Sohn, E. Y., In-jung, L. (2006): Folk medicinal knowledge and conservation status of some economically valued medicinal plants of District Swat Pakistan. - Lyonia 11(2): 101-113.

[18] Hammer, O., Harper, D. A. T., Ryan, P. D. (2001): PAST: Paleontological Statistics software package for education and data analysis. - Palaeontologia Electronica 4(1): 9.

[19] Hamrick, J. L. (2004): Response of forest trees to global environmental changes. - Forest Ecology and Management 197: 323-335.

[20] Hirzel, A. H., Le Lay, G. (2008): Habitat suitability modelling and niche theory. Journal of Applied Ecology 45: 1372-1381.

[21] IPCC (Intergovernmental Panel on Climate Change) (2007): Climate change: the physical science basis. Geneva, Switzerland.

[22] IPCC (Intergovernmental Panel on Climate Change) (2013): IPCC Fifth Assessment Report (AR5). Geneva: WMO, IPCC Secretariat.

[23] Lepš, J., Šmilauer, P. (2003): Multivariate analysis of ecological data using CANOCO. Cambridge University Press, New York. 
[24] Lindner, M., Maroschek, M., Netherer, S., Kremer, A., Barbati, A. J. G. G., Seidl, R., Delzon, S., Corona, P., Kolstrom, M., Lexer, M. J. Marchetti, M. (2009): Climate change impacts, adaptative capacity, and vulnerability of European forest ecosystems. - Forest Ecology and Management 259: 698-709.

[25] Lurgi, M., López, B. C., Montoya, J. M. (2012): Novel communities from climate change. - Philosophical Transactions of the Royal Society B: Biological Sciences 367: 2913-2922.

[26] Nadkarni, K. M. (1980): Indian Material Medica. - Bombay, India: Popular Parakshan Depot, pp. 180-190.

[27] NASA, NOAA. (2015): NASA, NOAA Find 2014 Warmest Year in Modern Record. Available in: <https://www.nasa.gov/press/2015/january/nasa-determines-2014-warmestyear-in-modern-record> Accessed 15 November 2017.

[28] Petit, R. J., Aguinagalde, I., De Beaulieu, J. L., Bittkau, C., Brewer, S., Cheddadi, R., Ennos, R. (2003): Glacial refugia: hotspots but not melting pots of genetic diversity. Science 300: 1563-1565.

[29] Pigliucci, M., Murren, C. J., Schlichting, C. D. (2006): Phenotypic plasticity and evolution by genetic assimilation. - Journal of Experimental Biology 209: 2362-2367.

[30] Rehfeldt, G. E., Wykoff, W. R., Ying, C. C. (2001): Physiologic plasticity, evolution, and impacts of a changing climate on Pinus contorta. - Climatic Change 50: 355-376.

[31] Sherry, R. A., Zhou, X., Gu, S., Arnone, J. A., Schimel, D. S., Verburg, P. S., Luo, Y. (2007): Divergence of reproductive phenology under climate warming. - Proceedings of the National Academy of Sciences 104(1): 198-202.

[32] Siddiqui, K. M., Mohammad, I., Ayaz, M. (1999): Forest ecosystem climate change impact assessment and adaptation strategies for Pakistan. - Climate Research 12: 195203.

[33] Singh, S. K., Rawat, G. S. (2000): Flora of Great Himalayan National Park. - Himachal Pradesh, 60-61.

[34] Song, M., Zhou, C., Ouyang H. (2004): Distributions of dominant tree Species on the Tibetan Plateau under current and future climate scenarios. - Mountain Research and Development 24: 166-173.

[35] Tewari, V. P., Verma, R. K., Von Gadow, K. (2017): Climate change effects in the Western Himalayan ecosystems of India: evidence and strategies. - Forest Ecosystems 4(1), 13.

[36] Usmanghani, K., Saeed, A., Alam, M. T. (1997): Indusyunic medicine. - Karachi, Pakistan: University of Karachi press, p.120.

[37] Walther, G. R. (2010): Community and ecosystem responses to recent climate change. Philosophical Transactions of the Royal Society B-Biological Sciences 365: 2019-2024. 